\title{
Интродукция поздно цветущих декоративных травянистых многолетников в Главном ботаническом саду РАН
}

\section{Introduction of late flowering ornamental herbaceous perennials in the Main Botanical Garden named after N. V. Tsitsin the Russian Academy of Sciences}

\author{
Кабанов А. В. \\ Kabanov A. V. \\ Главный ботанический сад им. Н. В. Цицина Российской академии наук, г. Москва, Россия. E-mail alex.kabanow@rambler.ru \\ Main Botanical Garden named after N. V. Tsitsin the Russian Academy of Sciences, Moscow, Russia
}

\begin{abstract}
Peфepam. В статье приводятся данные по интродукционному изучению поздно цветущих многолетних декоративных травянистых растений природной флоры умеренных регионов Земли. Представлен перечень семейств и родов, входящих в современный коллекционный фонд. Приведено географическое распределение поздно цветущих травянистых растений из коллекции Лаборатории декоративных растений ГБС РАН. В зависимости от срока начала цветения выделены четыре группы, представляющие все разнообразие коллекционного фонда поздно цветущих декоративных растений. Представлены пути дальнейшего развития коллекционного фонда, выделены регионы-доноры для интродукционной работы.
\end{abstract}

Ключевые слова. Декоративные травянистые растения, интродукция, природные виды, поздно цветущие растения.

Summary. The article presents data on the introduction study of late-flowering perennial ornamental herbaceous plants of the natural flora of temperate regions of the Earth. A list of families and genera included in the modern collection fund is presented. The geographical distribution of late flowering herbaceous plants from the Laboratory of ornamental plants collection of the Main Botanical Garden named after N. V. Tsitsin the Russian Academy of Sciences is given. Depending on the time of the beginning of flowering, four groups are distinguished, representing the entire diversity of the collection fund of late-flowering ornamental plants. The ways of further development of the collection fund are presented; donor regions for introduction work are highlighted.

Key words. Introduction, late-flowering plants, natural species, ornamental herbaceous plants.

Коллекционный фонд Лаборатории декоративных растений Главного ботанического сада им. Н. В. Цицина РАН (ЛДР ГБС РАН) уникальный как по объему представленных в нем таксонов, так и по географическому происхождению и экологической приуроченности растений (Травянистые декоративные ..., 2009).

В настоящее время в ЛДР ГБС РАН представлены коллекции, созданные как на основе классических способов формирования - с учетом метода родовых комплексов (Русанов, 1950) и эколого-фитоценотического способа (Трулевич, 1991), так и с учетом нового подхода, целью которого является формирования коллекций, перспективных для различных вариантов использования. Так, были созданы коллекции высокорослых декоративных растений, а в последнее время активно формируется коллекция поздно цветущих декоративных многолетников. Стоит отметить, что отбор поздно цветущих декоративных многолетних растений- весьма перспективное направление современной интродукционной работы, позволяющее подобрать ассортимент для осеннего городского озеленения.

При формировании коллекционного фонда поздно цветущих декоративных многолетних травянистых растений очень важно было ограничить рамки, внутри которых и происходит выбор объектов для интродукционного изучения. Основным критерием было наличие цветения осенью. Именно поэтому основу коллекции составили виды, цветение которых начинается с середины августа и продолжает- 
ся до сентября - октября. Однако при таком подходе не учитываются виды и целые рода, для которых характерно длительное цветение (Heliopsis Pers., Echinacea Moench и т.д.), зацветающие намного раньше (в июле), но их цветение, причем достаточно обильное, может продолжаться до октября, в случае же длительной и теплой осени некоторые виды могут цвести и до начала ноября (Coreopsis grandiflora Hogg. и т. д.). Также в коллекционный фонд были включены ряд родов, для которых характерно еще более длительное и достаточно равномерное по обилию, цветение, продолжающееся с весны и до осени - Bellis perennis L. или с июня до наступления сильных осенних заморозков - Viola cornuta L.

За весь период интродукционных исследований в ЛДР ГБС РАН (с 1948 по 2018 гг.) было проведено испытание 138 природных видов, относящихся к 78 родам и 27 семействам поздно цветущих многолетних декоративных травянистых растений. При этом не учитывались виды, для которых характерно повторное осеннее цветение (Filipendula vulgaris Moench и т. д.). Также не учитывались однолетние травянистые растения.

В настоящее время (по данным на октябрь 2018 г.) в коллекционный фонд входит 83 природных вида, относящихся к 51 роду (Aconitum L., Ageratina Spach, Anemone L., Apios Fabr., Arnica L., Aster L., Bellis L., Boltonia L'Hér., Campanula L., Chelone L., Cimicifuga Wernischek, Clematis Dill. ex L., Colchicum L., Coreopsis L., Cymbalaria Hill, Doellingeria Ness, Duchesnea Sm., Echinacea, Eurybia Cass., Euthamia (Nutt.) Elliott, Eutrochium Raf., Galatella Cass., Gypsophila L., Helenium L., Helianthus L., Heliopsis, Hosta Tratt., Inula L., Kalimeris (Cass.) Cass., Lamium L., Leucanthemella Tzvelev, Ligularia Cass., Lychnis L., Miscanthus Anderss., Monarda L., Oenothera L., Platycodon A.DC., Plectranthus L'Hér., Phlox L., Physostegia Benth., Potentilla L., Rudbeckia L., Sanguisorba (Ruppius) L., Saponaria L., Sedum L., Silphium L., Solidago L., Symphyotrichum Nees, Tradescantia Ruppius ex L., Vernonia Schreb., Viola L.), 16 семействам (Asteraceae Bercht. \& J.Presl, Campanulaceae Juss., Caryophyllaceae Juss., Colchicaceae DC., Commelinaceae Mirb., Crassulaceae J.St.-Hil., Fabaceae Lindl., Hostaceae Mathew (в настоящее время относится к семейству Asparagaceae Juss.), Lamiaceae Martinov, Onagraceae Juss., Poaceae Barnhart, Polemoniaceae Juss., Ranunculaceae Juss., Rosaceae Juss., Scrophulariaceae Juss., Violaceae Batsch).

Преобладающими в коллекционном фонде поздно цветущих многолетников являются представители семейства Asteraceae (25 родов, 44 вида). Столь значительный объем связан с тем, что долгое время именно этому семейству отводилось особое внимание при интродукционной работе (Кабанов, 2012; Кабанов 2013; Кабанов, 2016; Кабанов, 2017). Значительно менее репрезентативно представлены семейства Ranunculaceae (4 рода, 5 видов), Lamiaceae (4 рода, 4 вида), Rosaceae (3 рода, 4 вида), Caryophyllaceae (3 рода, 3 вида), Campanulaceae (2 рода, 3 вида), Scrophulariaceae (2 рода, 2 вида), Crassulaceae (1 род, 5 видов), Colchicaceae (1 род, 3 вида), Роасеае (1 род, 2 вида). Остальные семейства Hostaceae (Asparagaceae), Commelinaceae, Fabaceae, Polemoniaceae, Violaceae- представлены одним родом и одним видом.

В коллекции представлены виды, происходящие из различных регионов умеренной зоны Земли. При анализе регионов-доноров преобладающими являются представители Северной Америки (40 видов - 48,2 \%), Восточной Азии (25 видов - 30,1\%), Европы (13 видов - 15,7 \%). Видов с широким географическим распространением немного, так, видов, встречающихся в Евразии, - 4 (4,8 \%), видов, встречающихся в Евразии и Северной Африке, - 1 (1,2%)-Bellis perennis. Стоит отметить, что географическое распределение поздно цветущих растений связано с историей флор и в подавляющем большинстве случаев приурочено к рефугиумам. Именно с этим и связана относительная бедность флоры Европы (за исключением Средиземноморья, Крыма, Кавказа) и, напротив, значительное видовое разнообразие флор Северной Америки и Восточной Азии. При этом для дальнейшей интродукционной работы именно Северная Америка и Восточная Азия могут стать основными регионами-донорами. Так, перспектива использования североамериканских поздноцветущих представителей, в первую очередь семейства Asteraceae, связана с тем, что, несмотря на более теплый климат и значительно больший вегетационный период, многие регионы, в первую очередь США, могут быть местами наибольшего интродукционного интереса. Так, наибольшее число перспективных видов, уже прошедших интродукционное изучение в условиях Средней полосы России, приурочено к таким географическим районам, как Аппалачские горы, североамериканские прерии и Скалистые горы (Радионова, 2003). Часто при выборе североамериканских регионов-доноров ограничиваются лишь северными, северо-западными и се- 
веро-восточными штатами США, отличающимися умеренно-континентальным климатом, устойчивым снежным покровом и достаточным увлажнением, растительность которых представлена хвойно-широколиственными и широколиственными лесами, высокотравными и низкотравными прериями, равнинными и альпийскими лугами, а также скальными сообществами. Однако и более южные штаты могут стать регионами-донорами, в том случае, если за основу брать интродукцию растений из субальпийского пояса (Лапин и др., 1986).

Также достаточно перспективными регионами-донорами должны стать Тибет, северные районы Китая, Японии и Кореи. За период интродукционных исследований был привлечен значительный объем поздно цветущих дальневосточных видов (в пределах Российской Федерации), однако лишь немногие из них сохранились в современном коллекционном фонде. Именно поэтому восстановление в коллекции утраченных, но перспективных для Средней полосы России видов (поздно цветущие представители родов: Aconitum, Allium L., Codonopsis Wall., Calystegia R. Br., Sedum, Polygonum L. и т. д.), является приоритетной задачей. Интродукции поздно цветущих природных видов, происходящих из Южной Европы и Малой Азии, в настоящее время уделено недостаточно внимания. Это связано с тем, что для большинства из них требуется создание особых эдафических условий, кроме того, их длительное культивирование зачастую ограничивается неустойчивостью в культуре в связи со сложными условиями позднеосеннего, зимнего и ранневесеннего периодов. В то же время планируется увеличить представительство осенне-цветущих эфемероидов из данных регионов (представители родов Colchicum, Crocus L., Scilla L.).

При анализе сроков цветения можно выделить 4 группы видов, при этом основным критерием принадлежности к той или иной группе, были сроки начала цветения и его завершения:

1. Цветущие в весенне-летне-осенний период - характеризуются длительным цветением. Начало цветения в мае, завершение - в сентябре-октябре. Для представителей данной группы характерно прохождение всех фенофаз. Отмечается ежегодное обильное цветение, образование семян, в ряде случаев - самосева.

2. Цветущие в летне-осенний период - характеризуются длительным цветением. Начало цветения со второй половины июня - начала июля. Завершение цветения в сентябре-октябре. Для представителей данной группы характерно прохождение всех фенофаз. Ежегодное обильное цветение, образование семян, в ряде случаев - самосева.

3. Цветущие в позднелетний - осенний период - начало цветения с середины августа, завершение - в сентябре-октябре. Для представителей данной группы характерно прохождение всех фенофаз. Ежегодное обильное цветение, для отдельных представителей данной группы отмечено образование семян, в ряде случаев - массового самосева.

4. Цветущие осенью - начало цветения со второй половины сентября - начала октября и до сильных осенних заморозков. При этом обильное цветение наступает в октябре - в ряде случаев в начале ноябре (при условии теплой продолжительной осени). К этой группе относятся самые поздно цветущие растения. Для большинства представителей данной группы характерно нерегулярное, в ряде случаев необильное цветение, зачастую семена не завязываются или не вызревают (за исключением ранних по сроку цветения форм, а так же при наличии длительной теплой погоды осенью).

Представители первой группы (цветущие в весенне-летне-осенний период), немногочисленны и включают 4 природных вида: Bellis perennis, Lamium maculatum (L.) L., Duchesnea indica (Andrews) Focke (syn. Potentilla indica (Andrews) T. Wolf), Potentilla flagellaris Wild. ex Schlecht., относящихся к 3 семействам - Asteraceae, Lamiaceae и Rosaceae.

Представители второй группы (цветущие в летне-осенний период) более многочисленны и включают 22 природных вида: Arnica sachalinensis (Regel) A. Gray, Aster amellus L., Campanula carpatica Jacq., Campanula rapunculoides L., Coreopsis grandiflora, Cymbalaria muralis G. Gaertn., B. Mey. \& Scherb., Echinacea purpurea (L.) Moench, Echinacea angustifolia DC., Gypsophila pacifica Kom., Heliopsis helianthoides (L.) Sweet, Lychnis chalcedonica L., Monarda didyma L., Oenothera missouriensis Sims, Phlox paniculata L., Platycodon grandiflorus (Jacq.) A. DC., Potentilla nepalensis Hook., Rudbeckia laciniata L., Saponaria officinalis L., Sedum ewersii Ledeb., Sedum selskianum Regel et Maack, Tradescantia virginiana L., Viola cornuta, относящихся к 11 семействам - Asteraceae, Campanulaceae, Caryophyllaceae, 
Crassulaceae, Commelinaceae, Lamiaceae, Onagraceae, Polemoniaceae, Rosaceae, Scrophulariaceae и Violaceae. Ряд видов за счет обильного образования самосева образует достаточно устойчивые популяции (Heliopsis helianthoides, Rudbeckia laciniata), или же отмечается регулярное образование массового самосева без образования длительно существующих популяций (Cymbalaria muralis, Echinacea purpurea, Lychnis chalcedonica, Viola cornuta).

Представители третьей группы (цветущие в поздне-летний - осенний период) включают 33 природных вида: Aconitum arcuatum Maxim., Anemone hupehensis (Lemoine) Lemoine, Aster ageratoides Turcz., Aster tataricus L. f., Chelone obliqua L., Colchicum byzantinum Ker Gawl., Doellingeria umbellata (Mill.) Nees, Eurybia macrophylla (L.) Cass, Euthamia graminifolia (L.) Nutt., Eutrochium fistulosum (Barratt) E. E. Lamont, Eutrochium purpureum (L.) E. E. Lamont, Eurybia divaricata (L.) G. L. Nesom, Galatella linosyris (L.) Rchb. f., Galatella sedifolia (L.) Greuter (syn. Aster sedifolius L.), Helenium autumnale L. (средние по сроку цветения формы), Hosta lancifolia (Thunb.) Engl., Inula racemosa Hook. f., Kalimeris incisa (Fisch.) DC., Kalimeris mongolica (Franch.) Kitam., Ligularia dentata (A.Gray) H. Hara, Miscanthus sacchariflorus (Maxim.) Franch., Miscanthus sinensis Andersson, Physostegia virginiana (L.) Benth., Rudbeckia fulgida Aiton, Sanguisorba parviflora Takeda, Sedum caucasicum (Grossh.) Boriss., Sedum spectabile R. Br., Sedum telephium L., Silphium perfoliatum L., Symphyotrichum cordifolium (L.) G. L. Nesom, Solidago canadensis L., Solidago caesia L., Solidago flexicaulis L., относящихся к 9 семействам: Asteraceae, Colchicaceae, Crassulaceae, Hostaceae, Lamiaceae, Poaceae, Ranunculaceae, Rosaceae и Scrophulariaceae. Один вид, относящийся к данной группе, является инвазионным (Solidago canadensis), ряд видов - потенциально инвазионны (Eutrochium purpureum, Kalimeris incisa), некоторые виды способны образовывать устойчивые самоподдерживающиеся за счет самосева (Silphium perfoliatum, Ligularia dentata) или активного вегетативного разрастания (Miscanthus sacchariflorus, Aster ageratoides, Euthamia graminifolia) популяции.

Представители четвертой группы (цветущие осенью) включают 24 природных вида: Ageratina altissima (L.) King et H. E. Robins., Ageratina aromatica (L.) Spach, Apios americana Medik., Colchicum autumnale L., Colchicum speciosum Steven, Eutrochium dubium (Willd. ex Poir.) E. E. Lamont, Boltonia asteroides (L.) L'Hér., Cimicifuga heracliefolia Kom., Cimicifuga simplex (Wozmsk. ex D1.) Ledeb., Clematis heracleifolia DC., Coreopsis tripteris L., Helianthus decapetalus L., Helianthus microcephalus Torr. et Gray, Helianthus mollis Lam., Leucanthemella serotina (L.) Tzvelev, Plectranthus excisus Maxim., Solidago rigida L., Symphyotrichum dumosum (L.) G. L. Nesom, Symphyotrichum ericoides (L.) G. L. Nesom, Symphyotrichum laeve (L.) A. et D. Löve, Symphyotrichum lateriflorum (L.) A. Löve et D. Löve, Symphyotrichum novaeangliae (L.) G. L. Nesom., Symphyotrichum novi-belgii (L.) G. L. Nesom., Vernonia arkansana DC. (syn. Vernonia crinita Raf.), относящихся к 5 семействам: Asteraceae, Colchicaceae, Fabaceae, Lamiaceae и Ranunculaceae. Стоит отметить, что представители этой группы не обладают потенциальной инвазионностью в условиях Средней полосы России.

В заключение стоит отметить, что интродукционная работа по привлечению новых для Средней полосы России поздно цветущих декоративных травянистых растений активно продолжается. Выделены основные регионы-доноры, собрана информация по ранее испытанным в культуре природным видам, выбраны перспективные для интродукции роды. Помимо интродукции природных видов, ведется планомерная работа по оценке перспективности сортов, полученных на основе природных видов. Особое внимание при интродукции уделяется и выявлению потенциальной инвазионности видов. Наиболее перспективные для региона виды рекомендуются для городского озеленения. Стоит отметить, что перечень рекомендованных видов и сортов для массового городского озеленения регулярно критически пересматривается.

Работа выполнена в рамках ГЗ ГБС РАН (№ 118021490111-5).

\section{ЛИТЕРАТУРА}

Лапин П. И., Некрасов В. И., Плотникова Л. С., Скворцов А. К., Элайс Т. С. Интродукция и охрана растений в СССР и США. - М.: Наука, 1986. - 128 с. 
Кабанов $\boldsymbol{A}$. В. Принципы формирования коллекционных фондов отдела декоративных растений ГБС РАН на примере коллекции представителей семейства астровые» // Материалы межрегион. науч.-практ. конф., посвящ. 35-летию кафедры общей биологии и ботаники и ботанического сада ИвГУ (28-29 сентября 2012 г., г. Иваново). Иваново: Ив. гос. ун-т, 2012. - С. 209-2012.

Кабанов $\boldsymbol{A}$. $\boldsymbol{B}$. Поздно цветущие представители Asteraceae, перспективные для введения в городское озеленение // Матеріали МіжнародноЇ науковоЇ конференціЇ "Роль ботанічних садів і дендропарків у збереженні та збагаченні біологічного різноманіття урбанізованих територій. - КиЇв, 2013. - С. 219-220.

Кабанов $\boldsymbol{A}$. В. Коллекция поздно цветущих астровых ГБС РАН: история, современное состояние, перспективы развития // Бюл. ГБС, 2016. - № 4. - Вып. 202. - С. 26-32.

Кабанов $\boldsymbol{A}$. В. Формирование коллекции многолетних травянистых североамериканских представителей семейства Asteraceae в Главном ботаническом саду РАН // Hortus Botanicus, 2017 - Т. 12 - С. 157-163.

$\boldsymbol{P a d u о н о в \boldsymbol { E }} \boldsymbol{E}$. $\boldsymbol{C}$. Растительный покров Северной Америки как источник интродукции декоративных травянистых многолетников в Средней полосе России: Автореф. дис. ... канд. биол. наук. - М., 2003. - 22 с.

Русанов Ф. Н. Новые методы интродукции растений // Бюллетень Главного ботанического сада, 1950. - Вып. 7. - C. 27-36.

Травянистые декоративные многолетники Главного ботанического сада им. Н. В. Цицина РАН: 60 лет интродукции / отв. ред. А. С. Демидов; Учреждение РАН Гл. ботан. сад им. Н. В. Цицина РАН. - М.: Наука, 2009. $396 \mathrm{c}$.

Трулевич Н. В. Эколого-фитоценотические основы интродукции растений. - М.: Наука, 1991. - 213 с. 